University for Business and Technology in Kosovo

UBT Knowledge Center

UBT International Conference

2017 UBT International Conference

Oct 29th, 5:00 PM - 5:15 PM

\title{
Investigation of ternary binder based systems in terms of Calorimetry, Shrinkage and In-Situ XRD
}

Anxhelina Qorllari

Fan S. Noli University, anxhelinaqorllari@gmail.com

Elsa Qoku

TU Bergakademie Freiberg, elsa.qoku@ikgb.tu-freiberg.de

Thomas A. Bier

TU Bergakademie Freiberg, thomas.bier@ikgb.tu-freiberg.de

Teuta Dilo

University of Tirana, teuta.dilo@fshn.edu.al

Follow this and additional works at: https://knowledgecenter.ubt-uni.net/conference

Part of the Civil Engineering Commons

\section{Recommended Citation}

Qorllari, Anxhelina; Qoku, Elsa; Bier, Thomas A.; and Dilo, Teuta, "Investigation of ternary binder based systems in terms of Calorimetry, Shrinkage and In-Situ XRD" (2017). UBT International Conference. 43. https://knowledgecenter.ubt-uni.net/conference/2017/all-events/43

This Event is brought to you for free and open access by the Publication and Journals at UBT Knowledge Center. It has been accepted for inclusion in UBT International Conference by an authorized administrator of UBT Knowledge Center. For more information, please contact knowledge.center@ubt-uni.net. 


\title{
Investigation of Ternary Binder Based Systems in Terms of Calorimetry, Shrinkage and In-Situ XRD
}

\author{
QORLLARI Anxhelina ${ }^{1, a}$, QOKU Elsa ${ }^{2, b}$, BIER Thomas A. 2, c , DILO Teuta ${ }^{3, d}$ \\ ${ }^{1}$ Department of Mathematics, Informatics and Physics, Faculty of Natural and \\ Human Sciences, Fan S. Noli University, Str."Nënë Tereza", Ish-Divizioni, Korça, \\ Albania \\ ${ }^{2}$ Institut für Keramik, Glas- und Baustofftechnik, TU Bergakademie Freiberg, \\ Leipziger Straße 28,D- 09596 Freiberg, Germany \\ ${ }^{3}$ Physics Department, Faculty of Natural Science, University of Tirana, Bulevardi \\ Zogu i Pare, Tirana, Albania \\ aanxhelinaqorllari@gmail.com, belsa.qoku@ikgb.tu-freiberg.de, \\ cthomas.bier@ikgb.tu-freiberg.de, ${ }^{\mathrm{d}}$ teuta.dilo@fshn.edu.al
}

\begin{abstract}
Ternary binders are defined in this study as compositions of Calcium Aluminate Cement (CAC), Ordinary Portland Cement (OPC) and Calcium Sulfate $(C \bar{S})$. Several mixtures were studied, calorimetric and shrinkage technique has been used to follow the hydration during 24 hours. The XRD technique is used as support for the analysis of the hydration products. The results have shown that the initial amount of $C A C$ and $C \bar{S}$ play a key role in the hydration of $P C / C A C / C \bar{S}$ mixtures especially affecting the formation of ettringite. The mechanism of reactions (hydration kinetic) and the reactions speed (acceleration or retardation) depends by the aggregates (LSP, QP) put in the different binders. The addition of re-dispersible powders induced retardation in hydration kinetics, longer setting times and also changed the dimensional stability. Comparison of the phase development monitored by in-situ XRD was performed.
\end{abstract}

Keywords: Ternary binders, Calorimetry, Shrinkage, Re-dispersible powder

\section{Introduction}

Ternary binder systems show different phase compositions and microstructure compared topure Portland cement. Whereas Portland cement is widely studied, there exists very little published data on the performance of these materials over time.In ternary systems, different binders are combined in order to achieve specific technological properties. These ternary binders are widely used in construction field due to their advantages of quick open and shrinkage composition. As known to all, different content of the three basic raw materials, Portland Cement (OPC), Calcium Aluminate Cement (CAC), and Calcium Sulfate $(C \bar{S})$, can affect the function of hydration kinetics, workability and shrinkage or expansion.To find out the exact influences of the aggregates and the re-dispersible powderon the final products in the early time, three typical ternary binder systems are selected as study subject. 


\section{Experimental}

\section{Materials and studied compositions}

The mix design of the systems used is given in Table 1.Three mortars series were composed of different binders, lime stone powder (LSP), quartz powder (QP), and a re-dispersible powder from Wacker (RE $525 \mathrm{Z}$ ). The water-binder-ratio was kept constant at $w / b=0.40$. A CEM I 42.5R was used for the OPC, a Ciment Fondu Lafarge (CFL) with rapidly hardening was used as Calcium Aluminate Cement and anhydrite was used as sulfate source (Raddichem) [1].

All mortars were mixed in a Hobart type mixer according to DIN EN 196.1

Table 1. Compositions of the samples investigated

\begin{tabular}{|c|c|c|c|c|c|c|}
\hline System & OPC & CAC & $\mathbf{C} \overline{\boldsymbol{S}}$ & LSP/QP & W/B & RP \\
\hline $\mathbf{4}$ & 15.5 & 24.5 & 10 & 50 & 0.4 & 4 \\
\hline $\mathbf{5}$ & 6.5 & 32.25 & 11.25 & 50 & 0.4 & 4 \\
\hline $\mathbf{6}$ & 0 & 35 & 15 & 50 & 0.4 & 4 \\
\hline
\end{tabular}

\section{Characterization and methods used}

Measurement of heat flow by calorimetry test. The calorimeter was used to measure the heat flow of paste specimen. The measuring principle of the calorimeter is the thermometer of the block will detect the difference between the target-specimen and the reference specimen. Then the sensor of the thermometer transfers temperature difference into voltage difference which is measured by a digital multimeter. After that, the signal will be recorded by the computer through com-port. In the end, the signals turn into the form of heat flow curve via the data of recording software OMI (online measurement and imaging). To prepare the paste $3 \mathrm{gr}$ of binder were mixed with $1.2 \mathrm{gr}$ of water. In this research, all specimens are tested using the external method [2-4].

Measurement of early shrinkage. Shrinkage tests are measured by a modifiedversion of the German classical "Schwindrinne" measuring 4x6x $25 \mathrm{~cm}$. Functional measure components are a movable gate and a linear transducer. The transducer connects with a data collector, which transfers the length variable into digital signal. To measure shrinkage behavior, the channel should be firstly prepared, considering that the measurement can be started quickly after the filling of specimen. In our case the measurements started after ten minutes of water additionand lasted for the first 24 hours. Then the linear transducer needs to be fixed and be adjusted in a middle position, which makes the positive and negative length variable detectable. The initial length of the specimen is all controlled in about $25 \mathrm{~cm}$. To prepare the paste specimen for the shrinkage measurements 1000 gr of binder and 400 gr of water were mixed. All specimens are tested for $24 \mathrm{~h}$, in which every $50 \mathrm{~ms}$ a measurement is recorded [5].

Phase development by XRD observation.To analyze the phase development by In-situ X-ray diffraction the paste specimen were prepared by mixing $10 \mathrm{gr}$ of binder and $4 \mathrm{gr}$ of water.X- 
rayanalyses were performed using a PANalytical X'pert Pro MPD PW 3040/60 with a PIXcel detector. Samples were mixed with water, filled in a mold sample holder and covered with Kapton foil. The total preparation time was always $\sim 1$ minute in order to have always the same starting time. Diffractograms were taken with Cu radiation $(40 \mathrm{kV}$ and $40 \mathrm{~mA})$ in the range of $5 . . .50^{\circ} 2 \Theta$. The step size was about $0.013^{\circ}$ with an effective counting time of $19 \mathrm{~s}$ per step. The detector was set to maximum active length $\left(3.347^{\circ}\right)$. Each diffractogram was acquired in about $5 \mathrm{~min}$. In total, 270 consecutive diffractograms were taken.

\section{Results}

Calorimetry. Fig. 1-2 show the heat flow during the first 24 hours for systems 4, 5 and 6 . Heat flow under external mode has been measured for ternary binders containing Lime Stone Powder (LSP) or Quartz Powder (QP) with and without the addition of a re-dispersible powder. All curves are characterized by two main peaks before 10 hours. System 4 characterized by one main intense peak. Heat measurements were done on these systems to compare the effect of LSP or QP on the hydration kinetics. The addition of these fillers seems to not affect the mechanisms of hydration. The hydration development in both cases (with LSP or QP) is similar.As shown in Fig. 1 the use of QP as compared to LSP leads to higher peaks for system 4, lower peaks for system 5 and higher second peak and lower first peak for system 6 .

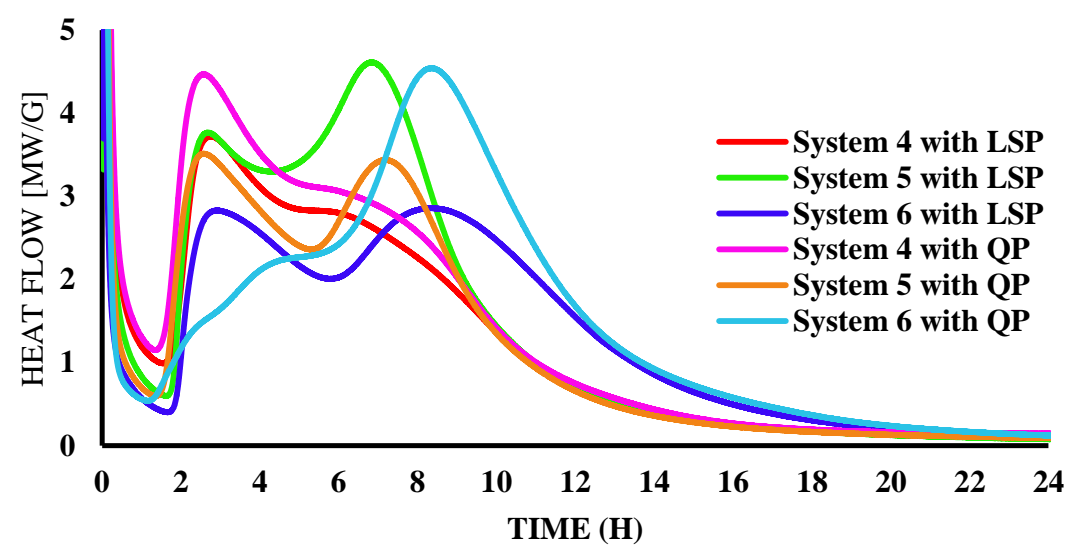

Figure 1. Heat flow for the ternary binder systems without RP containing LSP or QP

Fig. 2 demonstrates the effect of re-dispersible powders addition to ternary binders containing LSP. In this case higher heat flow values are obtained and an acceleration of the hydration process compared to the systems without re-dispersible powder is observed. 


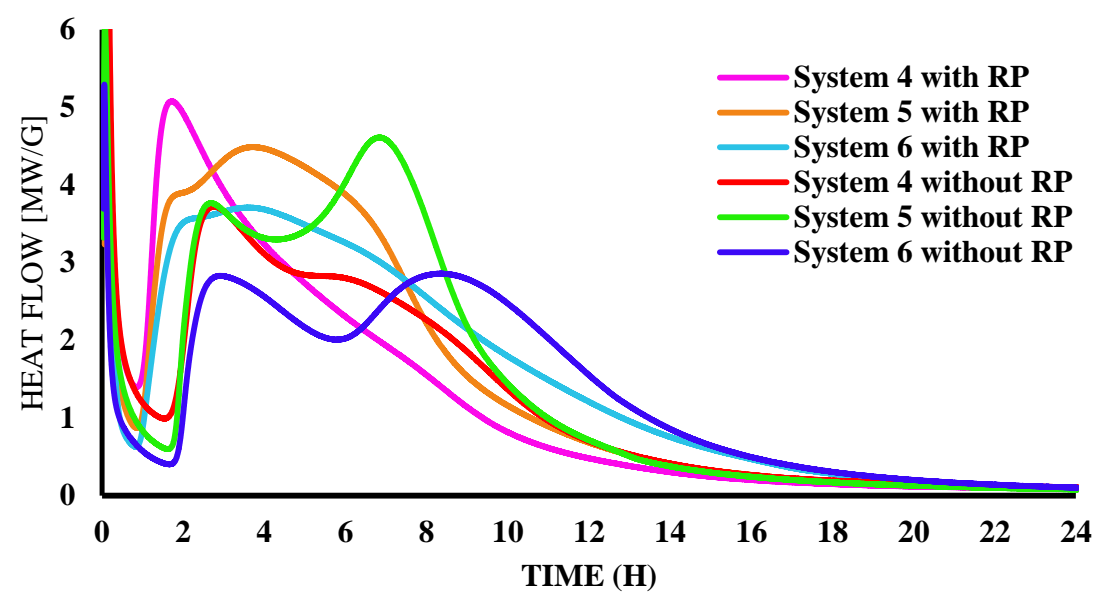

Figure 2. Heat flow for the ternary binder systems containing LSP with and without RP

Shrinkage. Fig. 3-4 show the shrinkage under uncovered (drying) conditions during the first 24 hours for systems 4,5 and 6 . Shrinkage has been measured for ternary binders containing LSP or QP with and without the addition of a re-dispersible powder. All curves show the plastic shrinkage at the beginning of time. Plastic shrinkage occurs as soon as water is added to the powder, due to chemical reactions and due to the loss of water by evaporation. At the end of plastic phase a slight expansion is observed for these ternary binders. As shown in Fig. 3 for systems 4 and 5 with LSP a higher plastic shrinkage is observed. For system 6 this effect is not pronounced.

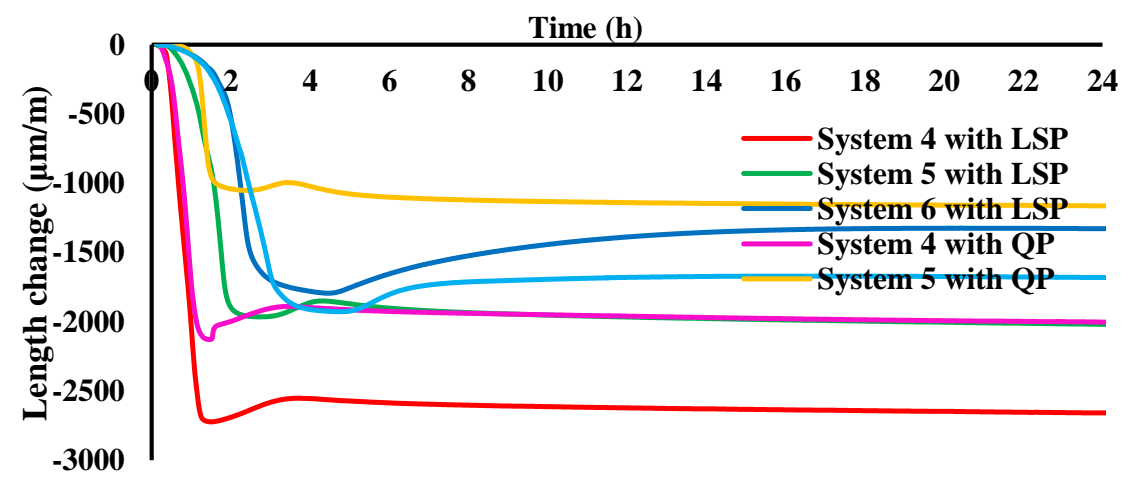

Figure 3. Early shrinkage for ternary binder systems without RP with LSP or QP measured in uncovered conditions

When re-dispersible powders are added as it is demonstrates in Fig. 4 for systems containing LSP, plastic shrinkage is pronouncedly reduced. The addition of re-dispersible powder tends to increase slightly the expansion. 
Time (h)

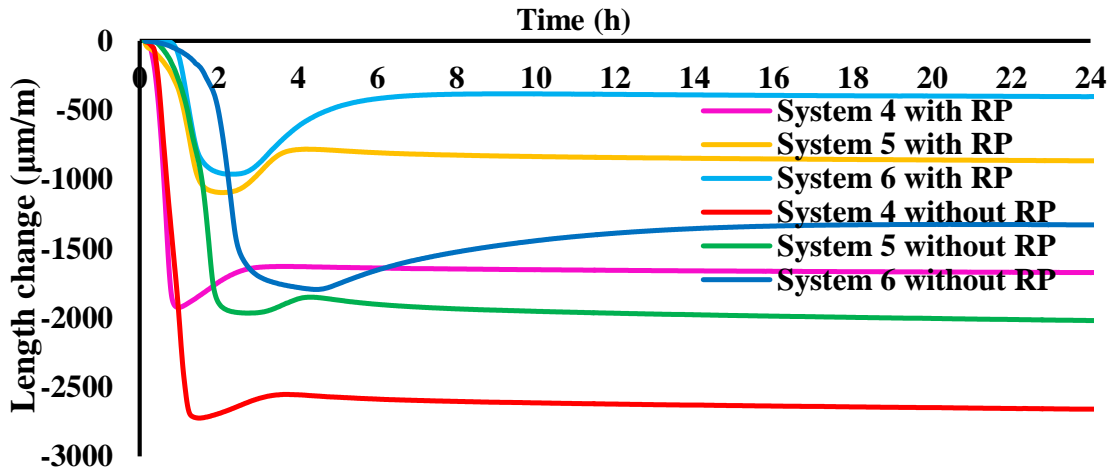

Figure 4. Early Shrinkage for ternary binder systems with LSP with and without RP measured in uncovered conditions

XRD. X-ray peaks of anhydrite, ettringite, calcium aluminum oxide and calcite for systems with LSP or quartz for systems with QP had been observed. Anhydrite and calcium aluminum oxidephases reacts with gypsum in solution to form ettringite. Precipitation of initial hydrates such as ettringite at the first hours of hydration proses occurs and generates an outburst of heat. The addition of a re-dispersible powder directly affects the hydration process.

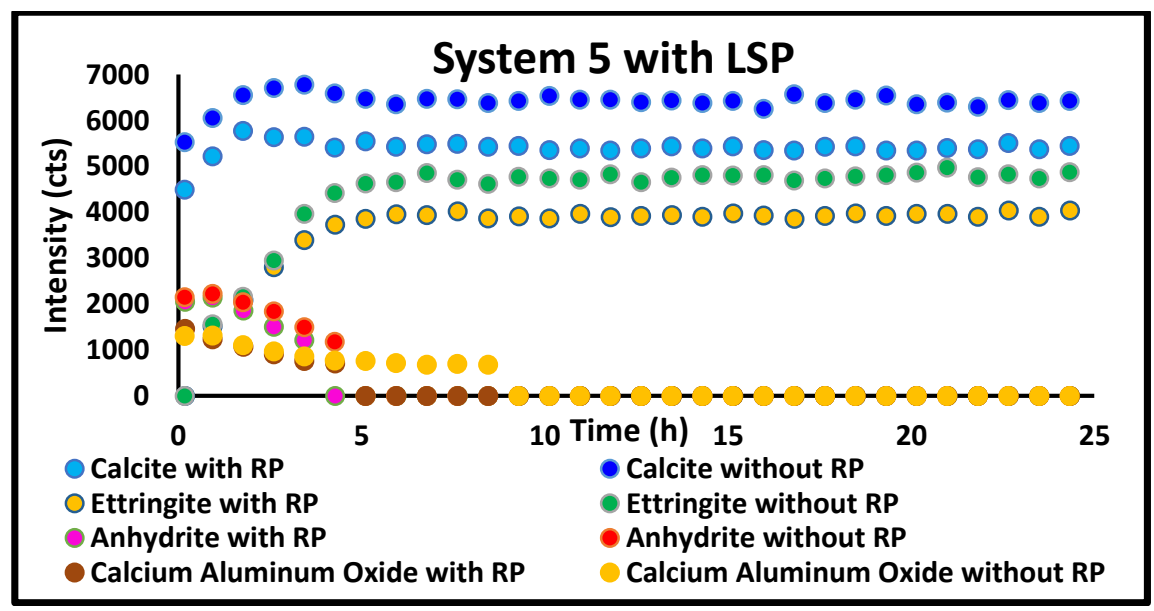

Figure 5. Dependence of the Intensity by the timefor system 5 with LSP with and without RP

Fig. 5 shows the influence of re-dispersible powders on the phase formation during the first 24 hours of hydration for system 5 with LSP. The consumption of calcium aluminum oxide is delayed by the addition of re-dispersible powder. Furthermore lower amounts of ettringite are formed as lower values of intensity are detected. 


\section{Conclusions}

The heat flow of these ternary binder systems is characterized by two main peaks before 10 hours. The addition of re-dispersible powders on the systems produces higher values of heat flow and accelerates the hydration process.

The addition of re-dispersible powder tends to reduce the plastic shrinkage and to increase slightly the expansion.

Anhydrite and calcium aluminum oxide consumes at the first hours of the hydration process to form ettringite.

The intensity of the peaks of hydration products tends to decrease when adding re-dispersible powder.

\section{References}

1. Bier Thomas, Bajrami Adrian, Westphal Torsten, Qoku Elsa and Qorllari Anxhelina, "Influence of Re-dispersible Powders on Very Early Shrinkage in Functional Mortars",Advanced Materials Research Vol. 1129 (2015) pp 77, (c) (2015) Trans Tech Publications, Switzerland

2. Peter C. Hewlett, "Lea's Chemistry of Cement and Concrete", ISBN: 0750662565, Elsevier Science \& Technology Books, Chap. 8, p. 344, January (2004).

3. Kighelman Julien,"Hydration and Structure Development of Ternary Binder System as used in Self-Levelling Compounds", PhD thesis No. 3777 (2007)

4. Séverine LAMBERET,Durability of ternary binders based on Portland cement, Calcium Aluminate Cement and Calcium Sulfate. PhD thesis NO 3151 (2005)

5. Keisuke Takahashi, Effects of Mixing and Pumping Energy on Technological and Microstructural Properties of Cement-based Mortars, Technical University Bergakademie Freiberg, PhD thesis, Freiberg, Germany, (2014) 